\title{
ALGUNOS DATOS SOBRE LA OBRA DE ROBERTO MONTENEGRO EN MALLORCA
}

JULIETA ORTIZ GAITÁN

Mallorca fue refugio de pintores y artistas cuando la Gran Guerra de 1914 puso fin a toda una bella época de confianzas y excesos, que tuvo como metrópoli representativa y deslumbrante al París finisecular. En esta ciudad se había dado la eclosión de ismos que dieron paso a los conceptos del arte moderno, resultado de una ebullición cultural de inquietud y experimentación constante por parte de los pintores establecidos de tiempo atrás en los barrios parisinos. De todos los puntos del orbe acudían a participar en el entusiasmo por las nuevas expresiones del arte, y los pintores mexicanos no fueron la excepción.

Roberto Montenegro llegó a París en 1906 gozando de una pensión otorgada por el Ministerio de Instrucción Pública y Bellas Artes, integrándose a la vida artística europea en un largo periodo que termina con el regreso a su patria en 1919. ${ }^{1}$ Todo hace suponer que el joven participó de la fascinación ejercida por la Ciudad Luz y por el raudal de conocimientos y vivencias que le fueron accesibles, no obstante, su modus vivendi se vio interrumpidoabruptamente con el estallido del conflicto bélico que habría de involucrar a Europa y a América en la primera de las dos guerras, llamadas mundiales, de este siglo XX.

Como casi todos los extranjeros en París, tuvo que buscar la manera de regresar a su patria, liquidando sus asuntos no sin pesar, para partir hacia Barcelona con la intención de conseguir pasaje a América. Pero las continuas incursiones de submarinos y barcos de guerra dificultaban el tránsito normal de "paquebotes", por lo que la salida se retrasaba una y otra vez. Así las cosas y después de haberse recreado en la ciudad, en sus museos, sus parques de frondosos castaños y arquitectura de "líneas danzarinas" a

\footnotetext{
${ }^{1}$ Este periodo se ve interrumpido de 1910 a 1912 cuando Montenegro regresa a México, participando, entre otras, en la Exposición de las Fiestas del Centenario.
} 
lo Gaudí, decide pasar unos días en el Puerto de Pollensa, Mallorca, donde previamente se había instalado su maestro Hermen Anglada Camarasa.

"Promesas de nueva vida ".,"

Roberto Montenegro llegó a Mallorca, España, a los veintisiete años de edad, con la intención de quedarse una corta temporada mientras encuentra la manera de regresar a México, pero su estancia mallorquina se prolongará por cuatro años, los cuatro años "más bellos" de su vida. ${ }^{2} \mathrm{Se}$ instala en el Puerto de Pollensa, a sesenta kilómetros al noreste de Palma, en una casa de dos pisos en cuya planta baja vivía una familia de pescadores, Juan Cerdá, su mujer y sus tres hijos, iniciando una vida sencilla a tono con el ambiente idílico que le rodeaba. Se pone en contacto con el maestro Anglada Camarasa y sus condiscípulos de París, quienes formarán la llamada escuela pollensina, movimiento pictórico afluente del modernismo catalán.

Hermen Anglada Camarasa, pintor catalán, fue quien pugnó, desde París, por este encuentro en Pollensa. Alejado de las vanguardias parisinas, alentó a sus discípulos - principalmente latinoamericanos-a incursionar en valores autóctonos como principal motivación de su trabajo pictórico. Su estilo, imbuido en el postsimbolismo y teniendo como base las exuberancias cromáticas del impresionismo tardío, condujo al joven Montenegro a una visión plástica nueva que marca un giro inesperado y opuesto, respecto a su formación académica anterior. Hasta entonces, Montenegro había sido el ilustrador de la Revista Moderna, el pintor académico-modernista afecto a los temas ambiguos y tortuosos, el estudiante de arte cautivado por la pintura española y desconcertado por las vanguardias parisinas, pero su periodo mallorquino vio florecer las formas y los colores de manera abundante y generosa, en temas sencillos tomados del mundo luminoso que le rodeaba y que despertó, sin duda, un nuevo gusto por vivir.

No hay que olvidar, por otro lado, que el anhelo de encontrar una arcadia estaba presente, desde tiempo atrás, en la cultura europea. Diversos grupos de seres humanos, una y otra vez, creyeron encontrar las utopías son̆adas en distintos tiempos y lugares. Nuestros pintores, marca-

\footnotetext{
${ }^{2}$ Montenegro describe con emoción y nostalgia estos años mallorquinos en sus memorias Planos en el tiempo, México, sin editor, 1962.
} 
dos con el hastío y el desencanto de la "civilización" y huyendo además de los horrores de la guerra, construyeron en las playas recoletas de Mallorca, su propia edad dorada.

La cala de San Vicente, que por ese entonces debió ser un lugar virgen, era frecuentada por Montenegro, Jorge Enciso, Tito Cittadini y Gregorio López Naguil, quienes en compañía de Rugena Khvoshinsky, establecieron una alegre cofradía en cabañas de pescadores convertidas en talleres de pintura y de convivencia bohemia. ${ }^{3}$ Rugena, única mujer a quien Montenegro recordará con emoción, era estudiante de arte y esposa de un diplomático ruso. Su retrato, ejecutado al óleo por su amigo mexicano, nos entrega una personalidad atractiva, de rostro fino y lleno de energía vital (foto 1). El grupo se instala en la cala de San Vicente, al parecer por una corta temporada, en 1913, según relata Ferrer Gibert. La vida en estas playas debió colmar con creces los anhelos por reencontrar a la naturaleza, en aquellas cabañas-ateliers cuyos ocupantes, en vez de mirar a los bulevares citadinos de grises cielos, se solazaban con los azules deslumbrantes del Mediterráneo y el murmullo acompasado de las olas. En su interior había un

pintoresco contraste que bajo una especie de patio recubierto por verde pinareda $\ldots$ ofrecían caballetes, paletas, unos libros, tubos de pintura, tablitas y telas abocetadas esparcidas y mezcladas con platos y enseres de cocina; varias hamacas recubiertas por ricas pieles y por una echarpe dejada al descuido, tendidas entre redes puestas a secar al sol ..."

Hay dos estancias entonces, de Montenegro en Mallorca: la primera en 1913, al parecer corta, cuando conoce la isla en compañía de Enciso, Rugena, Cittadini y López Naguil, instalándose en las cabañas de la Cala de San Vicente. Con esta experiencia no debió haber sido dificil la decisión de regresar al año siguiente, por el conflicto bélico y en las condiciones narradas. Es entonces cuando se instala en el Puerto de Pollensa, llegando primero a la pensión que actualmente es el Hotel Miramar y posteriormente a su casita de dos pisos compartida con la familia Cerdá.

Otro lugar que Montenegro evocará de Mallorca es la Fortaleza, vetusta construcción que dáta dé siglo XVII enclavada en la Punta de la Avanzada o de Albercuix, península que cierra la Bahía de Pollensa. Ahí nuestro

\footnotetext{
${ }^{3}$ Pedro Ferrer Gibert, "Pollensa era ya meca de pintores extranjeros hace ya más de medio siglo" en Diario La Almudaina, Palma de Mallorca, 1913. Reproducido en el Diario de Mallorca, 10 de noviembre de 1963, p. 16.

${ }^{4}$ Ibid
} 
pintor pasaba temporadas como huésped en compañía del pintor argentino Roberto Ramaugé, cuyo sino era "gastar herencias" y quien la embelleció con obras de arte. De las reuniones que se llevaban a cabo en dicho lugar, Montenegro recuerda con especial emoción las veladas animadas por la guitarra de Andrés Segovia, amigo de ambos pintores.

Roberto Montenegro, por su parte, tuvo, además de palacios y cabañas de pescadores, hospedaje en casas pollensinas que le brindaron calidez familiar recién llegado a la isla. La pensión que le acogió - hoy Hotel Miramar-ostenta varios óleos recibidos probablemente en pago por su estancia, ya que el pintor mexicano "no andaba nada sobrado de dinero" ${ }^{4}{ }^{5}$ De estos cuadros hablaremos más adelante.

\section{Obra plástica}

Las relaciones de Montenegro le permitieron montar exposiciones y llegar a ser un pintor relativamente conocido, tan es así que fue contratado para decorar un salón en el Círculo Mallorquí de la ciudad de Palma, construcción decimonónica que actualmente es el Parlamento de las Islas Baleares y que aún ostenta lo que fue su primer trabajo de pintura mural realizado en $1919 .^{6}$

Respecto a la obra de caballete, pude conocer los mencionados óleos del actual Hotel Miramar, propiedad de la familia Sastre. Estos cuadros adornan el vestíbulo del Hotel y otros se encuentran en casa de dicha familia. Se trata de tres marinas y una naturaleza muerta; ésta consiste en la representación de un frutero, rebosante de uvas, destacadas sobre el fondo pálido y policromo de un espejo; el colorido es tenue, matizado en delicados tonos que van del púrpura a las transparencias del verde y de los sienas tostados. Es un óleo sobre tabla de 31 x $31.5 \mathrm{~cm}$, fechado en 1916 (foto 2).

En cuanto a las marinas, se apartan del esquema plástico tradicional hasta aquí en Montenegro: dos de ellas consisten en paisajes rocosos tratados supeditando el dibujo a manchas de color plano, con sutil influencia impresionista, sobre todo del impresionismo de Sorolla, de Regoyos y del propio Anglada. Ambas son óleos sobre tablas de $22 \times 22 \mathrm{~cm}$ y, aunque Montenegro no firmó estos cuadros, "es absolutamente seguro que son suyos". ${ }^{7} \mathrm{La}$

\footnotetext{
${ }^{5}$ Carta de Beatriz Anglada a Julieta Ortiz, 29 de marzo de 1985.

${ }^{6}$ Véase: Julieta Ortiz Gaitán, Roberto Montenegro: produccion mural (1919-1966), Tesis de Maestría en Historia del Arte, UNAM, F.F.v L., 1989.

${ }^{7}$ Testimonio oral de Beatriz Anglada y de María Sastre, actual dueña del Hotel Miramar.
} 
marina restante es en realidad un fondo marino en el que aparece un pez dorado como foco visual preponderante, suspendido en un universo líquido de opalescencias verdes, reflejos dorados y formas ondulantes; acusa grandes similitudes con algunos trabajos de Anglada; está ejecutada al óleo sobre tabla de $29 \times 30 \mathrm{~cm}$ y está firmada (fotos 3,4 y 5 ).

En la casa de la familia Sastre existe un buen autorretrato de Montenegro, realizado en óleo sobre cartón, de $50 \times 35 \mathrm{~cm}$ en el cual el pintor mexicano se ve como un hombre joven, muy tostado por el sol, el gesto adusto y la mirada melancólica. La factura y el color recuerdan un poco el trabajo de Gauguin en su época de Tahití. Al reverso de este trabajo, pintó Montenegro un bodegón también al óleo titulado Cap roij, que significa "cabeza roja" y se trata de un pescado así llamado y que forma con su cuerpo el motivo principal compositivo. Está sobre un plato, pintado en vivos tonos del más puro bermellón que resaltan sobre los fríos azules y verdes de la estructura cromática del fondo (fotos 6 y 7 ).

En 1917 se inaugura el Salón Arabe del centro de reuniones sociales llamado Sociedad La Veda con una exposición del pintor mexicano Roberto Montenegro, organizada por el pintor Gabriel Villalonga Olivar y el fotógrafo Matías Mut. La mayoría de las obras expuestas, dibujos y bocetos a pluma, no fueron muy apreciados ni tampoco un éxito económico, ya que se vendieron a cien y a sesenta y cinco pesetas respectivamente. Las modalidades del art nouveau no eran de la preferencia de los mallorquinos y, por lo que parece ser, la exposición pasó casi inadvertida; sin embargo como queda dicho, le dio a Montenegro la oportunidad de decorar un salón en el Círculo Mallorquín de la ciudad de Palma de Mallorca. Estos dibujos no están localizados.

Por otro lado, en la residencia del doctor Andrés Jaume Planes, en la ciudad de Palma, se encuentran dos trabajos que pueden considerarse bocetos de los murales realizados en el Círculo Mallorquín. Uno de ellos representa a un pescador cargando una gran almadraba (red) cuya figura alargada ocupa toda la superficie pictórica, tal como lo hace Herrán en algunos de sus cuadros (por ejemplo en Flora). La técnica que emplea Montenegro es mixta, óleo mezclado con algún otro tipo de pigmento, ya que el fondo es dorado plano, sobre papel, de $91 \times 40 \mathrm{~cm}$ (foto 8).

El otro cuadro corresponde a la figura de un pastor apacentando a sus animales, caminando alegremente entre grandes chumberas o nopaleras, anima su paso con la música de una gaita. Está realizado en la misma técnica mixta que el anterior, sobre papel, de $92 \times 257 \mathrm{~cm}$ (fotos 9 y 10). En estos trabajos apreciamos una concepción muy particular del paisaje mallorquino, con el mar, las escarpadas montañas y los árboles en primer 
plano que inclinan sus ramas entrelazadas, recordando en sus trazos de dibujo pulido, al arte japonés. Por su similitud con los murales del Círculo Mallorquín, realizados en 1919, lo más probable es que hayan sido pintados en la misma época, pero al no estar fechados, no se puede afirmar nada al respecto. Sin embargo, es seguro que están íntimamente ligados, formal y temáticamente, a los mencionados murales.

En la misma casa del doctor Jaume Planes, se encuentran tres óleos de su propiedad, de excelente factura, firmados por Roberto Montenegro: se trata de tres retratos de damas mallorquinas, de facciones finas y con los inconfundibles ojos verdes propios de la región, de $76 \times 131 \mathrm{~cm} ; 43 \times 53$ cm y $58 \times 48 \mathrm{~cm}$ (fotos 11,12 y 13 ).

En el Parlamento de las Islas Baleares, antigua sede del Círculo Mallorquín, se encuentra un dibujo, catalogado por los autores locales como autorretrato de Montenegro, fechado en 1918. Dentro de un concepto monocromo en tonos de sepia y dorados, está dibujado con trazos de carbón y lápiz blanco, este último para acentuar las luces; sobre cartón, de proporciones casi cuadradas, $45 \times 50 \mathrm{~cm}$ (foto 14). Los rasgos faciales no son los de Montenegro ni la edad corresponde, ya que se trata de un hombre mayor de los treintaiún años que tenía el pintor por entonces. Además lleva una especie de boina muy ceñida que, según me dijeron, empleaba para trabajar y que impide apreciar la configuración de la cabeza. Desde mi punto de vista, se trata seguramente del retrato de algún pintor compañero de trabajo de nuestro artista, pero en el Parlamento se afirma categóricamente que es un autorretrato, afirmación con la cual tengo mis reservas.

Para continuar esta relación de la obra mallorquina, en el Ayuntamiento de Palma se encuentra un cuadro atribuido a Montenegro que no tuve oportunidad de ver y que es posible se trate del mencionado por Luis Ripoll como el de la Pinacoteca de Palma ${ }^{8}$ Asimismo este autor consigna un retrato: "el del farolero del Port de Pollensa, Alberti, hombre amigo de los pintores, y una de cuyas hijas casó con López Naguil..."

A toda esta producción hay que añadir el que es, sin duda, el cuadro más conocido de pintura de caballete realizado por Montenegro en la isla: $E l$ pescador de Mallorca, realizado cerca de 1919 al óleo sobre tela, actualmen-

${ }^{8}$ En la actualidad no hay Pinacoteca en esta ciudad En el Ayuntamiento se encuentra una importante colección de pintura - galería de retratos de prohombres mallorquinos-entre la que está el mencionado cuadro atribuido a Montenegro, según me informaron en dicho lugar. Desafortunadamente, no lo pude comprobar.

${ }_{9}$ Luis Ripoll, "Roberto Montenegro, un genio de la pintura apenas conocido" en Día de Baleares, No. 20, Palma de Mallorca, España, mayo de 1982, p. 23. 
te en la colección del MUNAL. Este cuadro, titulado Mateo el Negro, fue uno de los que resultaron dañados cuando el vapor Montserrat que transportaba las pertenencias de Montenegro desde Europa con destino a Veracruz, sufrió una "avería gruesa" al colisionarse en Nueva York con el vapor americano San Marcos. Debido a este accidente, el cargamento, consistente en dos cajas, llegó a su destino en el siguiente estado: Una caja de "artículos artísticos" descargada del vapor español Buenos Aires en el Puerto de Veracruz el 4 de enero de 1921, y la segunda caja de "cuadros al óleo", del vapor español León XIII, el 31 de enero de 1921. Muchos cuadros y libros se dañaron con el percance por lo que Montenegro reclama a la compañía de seguros la indemnización correspondiente (foto 15). ${ }^{10}$

La galería Joan Oliver Maneu, de Palma de Mallorca, tuvo a bien mandarme una fotografía de un cuadro de Roberto Montenegro, realizado en 1919: Payesa mallorquina, óleo sobre tela, $76 \times 76 \mathrm{~cm}$, firmado: R. Montenegro 1919 Palma. Como lo indica el título, el cuadro representa a una mujer con atuendo típico, enmarcada por una ventana y portando frutas propias de la región. La figura emana cierto encanto no desprovisto de dignidad y mesura al lucir con naturalidad sus ropas tradicionales y recordarnos de paso, lo que serán las tehuanas y chinas poblanas que tanto entusiasmaron a los pintores mexicanos en el renacimiento nacionalista de los años veinte (foto 16).

\section{El regreso}

No obstante lo idílico de su vida en Mallorca, Roberto Montenegro decide regresar cuando las circunstancias son favorables para ello y así, en 1919, deja para siempre la mayor de las Islas Baleares. Después de detenerse en Nueva York, Montenegro se reintegrará al ámbito cultural mexicano en un periodo de gran actividad política y artística, iniciando además lo más fecundo y representativo de su obra mural. Pero la visión de Mallorca permanecerá en su mente y en su espíritu, recreando paisajes escarpados, playas, cielos dorados y bahías mediterráneas, al pintar a gran escala en los muros públicos, lo que debía ser la representación de México y sus costumbres. Los gérmenes del nacionalismo, de una paleta menos sombría, las figuras imbuidas de un sentido más humano y menos artificioso y

\footnotetext{
${ }^{10}$ Agradezco a Fausto Ramírez Rojas la identificación de El pescador de Mallorca como Mateo el Negro. Véase tesis: J. Ortiz Gaitán, Roberto Montenegro, producción mural .... Apéndice documental, documento 19 .
} 
el interés por los temas locales y las manifestaciones del arte popular, habían sido concebidos en Mallorca y cobrarían vida en la obra mexicana de los años veinte y treinta, cuando las condiciones y los requerimientos sociales permitieron su desarrollo total. El sustrato modernista permaneció, enriquecido con prodigalidad con el largo periodo europeo que completó la formación de Montenegro; pero fue sin duda, el contacto con el modernismo catalán y con la escuela pollensina particularmente, lo que motivó el cambio en su visión plástica produciendo lo que a la postre serían los rasgos distintivos de su obra.

Por otro lado, muchas fueron las circunstancias que convergieron para hacer de sus años en Mallorca una etapa especial de su vida, recordada y añorada después hasta sus últimos días, y sin duda también idealizada con el correr de los años. Pero sobre todo, tal vez, su propia energía creadora fue la principal fuente de bienestar y plenitud, estimulada por aquel paisaje

... grandioso, la fuga de las montañas en la Cala de San Vicente, la superposición de rocas altísimas coronadas por las legendarias ruinas del castillo del rey Don Jaime y las lejanías en el horizonte, con todas las gamas de azules y más azules que se diluían y eran motivos para pintar.....

\section{BIBLIOGRAFÍA}

Bota Totxo, Miguel

1977 "Roberto Montenegro, el pintor enamorat de Mallorca", en El Día de Baleares, Arte, Hoja de Lunes, Palma de Mallorca, España, 22 de agosto.

Ferrer Gilbert, Pedro

1913 "Pollensa era ya meca de pintores extranjeros hace ya más de medio siglo", en Diario La Almudaina, reproducido en el Diario de Mallorca, Palma de Mallorca, 10 de noviembre de 1963.

Montenegro, Roberto

1962 Planos en el Tiempo, México.

${ }^{11}$ Bota Totxo, Miguel, "Roberto Montenegro, el pintor enamorat de Mallorca", en El Día de Baleares, Arte, Hoja del Lunes, Palma de Mallorca, España, agosto 22 de 1977. 
Ortiz Gaitán, Julieta

1989 Raberto Montenegro." Producción mural (1919-1966), Tesis de Maestría en Historia del Arte, Facultad de Filosofia y Letras, UNAM, 1989.

Ripoll, Luis

1982 "Roberto Montenegro, un genio de la pintura apenas conocido", en El Día de Baleares, No. 20, Palma de Mallorca, España, mayo. 